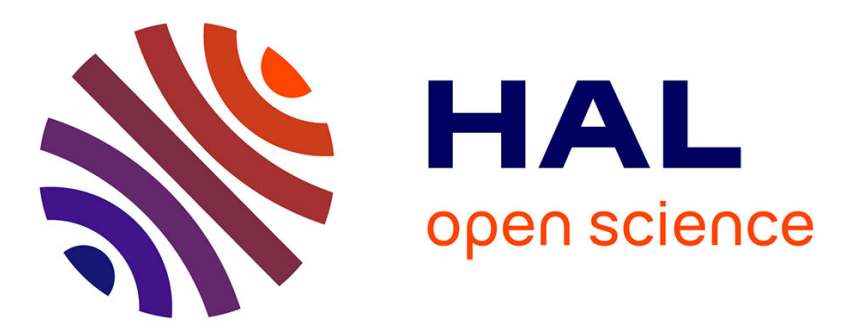

\title{
Shear-wave splitting beneath the Galápagos archipelago
}

Fabrice R. R. Fontaine, Emilie E. E. Hooft, Peter G. Burkett, Douglas R.

Toomey, Sean C. Solomon, Paul G. Silver

\section{To cite this version:}

Fabrice R. R. Fontaine, Emilie E. E. Hooft, Peter G. Burkett, Douglas R. Toomey, Sean C. Solomon, et al.. Shear-wave splitting beneath the Galápagos archipelago. Geophysical Research Letters, 2005, 32, 10.1029/2005GL024014 . hal-01249089

\section{HAL Id: hal-01249089 \\ https://hal.univ-reunion.fr/hal-01249089}

Submitted on 31 Dec 2015

HAL is a multi-disciplinary open access archive for the deposit and dissemination of scientific research documents, whether they are published or not. The documents may come from teaching and research institutions in France or abroad, or from public or private research centers.
L'archive ouverte pluridisciplinaire HAL, est destinée au dépôt et à la diffusion de documents scientifiques de niveau recherche, publiés ou non, émanant des établissements d'enseignement et de recherche français ou étrangers, des laboratoires publics ou privés. 


\title{
Shear-wave splitting beneath the Galápagos archipelago
}

\author{
Fabrice R. Fontaine, ${ }^{1}$ Emilie E. E. Hooft, ${ }^{2}$ Peter G. Burkett, ${ }^{3}$ Douglas R. Toomey, ${ }^{2}$ \\ Sean C. Solomon, ${ }^{3}$ and Paul G. Silver ${ }^{3}$
}

Received 7 July 2005; revised 25 September 2005; accepted 10 October 2005; published 8 November 2005.

[1] Shear-wave splitting measurements in the Galápagos archipelago show a rapid change from consistently oriented anisotropy to no measurable anisotropy. At the western edge of the archipelago delay times are $0.4-0.9 \mathrm{~s}$ and fast polarization directions are $81-109^{\circ} \mathrm{E}$. These directions are consistent with anisotropy resulting from shear of the asthenosphere by the overlying plate; there is no indication of fossil lithospheric anisotropy in the plate spreading direction. In contrast, beneath the center of the archipelago the upper mantle is isotropic or weakly anisotropic. The isotropic region coincides approximately with a volume of anomalously low upper mantle velocities, suggesting that the presence of melt may weaken the effects of fabric on anisotropy or that melt preferred orientation generates a vertical fast polarization direction. Alternatively, the complex flow field associated with a near-ridge hotspot may result in apparent isotropy. Citation: Fontaine, F. R., E. E. E. Hooft, P. G. Burkett, D. R. Toomey, S. C. Solomon, and P. G. Silver (2005), Shear-wave splitting beneath the Galápagos archipelago, Geophys. Res. Lett., 32, L21308, doi:10.1029/ 2005 GL024014.

\section{Introduction}

[2] The pattern of seismic anisotropy in the upper mantle near hotspots and mid-ocean ridges provides a means of constraining the mantle flow field and the distribution of partial melt. Because seismic velocity is anisotropic in single-crystal olivine, the most abundant mineral in the upper mantle, seismic anisotropy can be a consequence of the strain-induced lattice preferred orientation (LPO) of olivine crystals, whereby $a$-axes tend to orient parallel to the direction of maximum shear [Silver and Chan, 1991; Zhang and Karato, 1995]. In magma-producing regions, mantle melting influences anisotropy as well. Alignment of pockets of melt can produce anisotropy independent of LPO known as melt preferred orientation (MPO). Alternatively, laboratory experiments suggest that the $a$-axis alignment changes in the presence of melt [Holtzman et al., 2003]. The Galápagos region provides an ideal site for examining the competing contributions of flow and melting to seismic anisotropy at a near-ridge hotspot.

[3] Shear-wave splitting is a particularly robust manifestation of mantle anisotropy. The delay time $\delta t$ between

\footnotetext{
${ }^{1}$ Laboratoire de Tectonophysique, ISTEEM, CNRS/Université Montpellier II, Montpellier, France.

${ }^{2}$ Department of Geological Sciences, University of Oregon, Eugene, Oregon, USA.

${ }^{3}$ Department of Terrestrial Magnetism, Carnegie Institution of Washington, Washington, D. C., USA.
}

Copyright 2005 by the American Geophysical Union. 0094-8276/05/2005GL024014\$05.00 the two orthogonally polarized waves is proportional to the product of the magnitude of anisotropy and the thickness of the anisotropic region. The fast polarization direction $\phi$ depends on the orientation of the LPO or MPO. The LPO contributions to splitting may be either lithospheric or asthenospheric. Near a mid-ocean ridge both passive and active upwelling models predict that above $75 \mathrm{~km}$ depth flow aligns the $a$-axes of olivine crystals in the spreading direction and generates measurable anisotropy [Blackman and Kendall, 1997]. LPO within the lithosphere will reflect mantle flow conditions at the time when mantle material "froze" onto the base of the lithosphere, i.e., when local rates of shear strain fell below a threshold value. The asthenospheric contribution should reflect the plume flow field, a combination of radial spreading and shear induced by motion of the overlying plate [Sleep, 1990]. The influence of melt on splitting is not always straightforward, because melt appears to be capable of generating MPO as well as weakening LPO.

[4] Existing splitting observations at hotspots do not consistently display the pattern expected for asthenospheric plume flow. Near Hawaii and beneath the Eifel region the pattern of splitting has been interpreted as the result of plume flow [Walker et al., 2001; Walker, 2003], but at other hotspots there is no clear manifestation of this flow field. Splitting is undetectable beneath Tahiti, a result that has been interpreted as reflecting a vertical symmetry axis aligned by the upwelling Society plume or the absence of strong or consistently oriented mantle fabric [Russo and Okal, 1998]. At Iceland, a ridge-centered hotspot, fast polarization directions exhibit a systematic variation from NNE-SSW in western Iceland to NNW-SSE in eastern Iceland [Bjarnason et al., 2002]. This pattern is not easily reconciled with asthenospheric plume flow and has instead been interpreted as asthenospheric shear induced by NNW motion of the subasthenospheric mantle [Bjarnason et al., 2002].

[5] Studies of the Galápagos hotspot indicate that it is underlain by anomalously hot mantle that extends at least to the base of the upper mantle and is associated with upwelling and melting. High ${ }^{3} \mathrm{He} /{ }^{4} \mathrm{He}$ ratios [Graham et al., 1993] and modern volcanic activity [McBirney and Williams, 1969; Geist et al., 1988] show that the Galápagos hotspot is currently located under the western part of Isla Fernandina. Receiver function analysis suggests that, at the mantle transition zone, the upwelling volume is centered $40 \mathrm{~km}$ southwest of the center of Fernandina and has a radius of about $100 \mathrm{~km}$ [Hooft et al., 2003]. Body-wave tomography images plume-like patterns of low $\mathrm{P}$ and $\mathrm{S}$ velocities beneath the Galápagos hotspot in the upper mantle, but in the lower mantle the resolved $\mathrm{P}$ and $\mathrm{S}$ structures differ [Montelli et al., 2004a, 2004b]. 


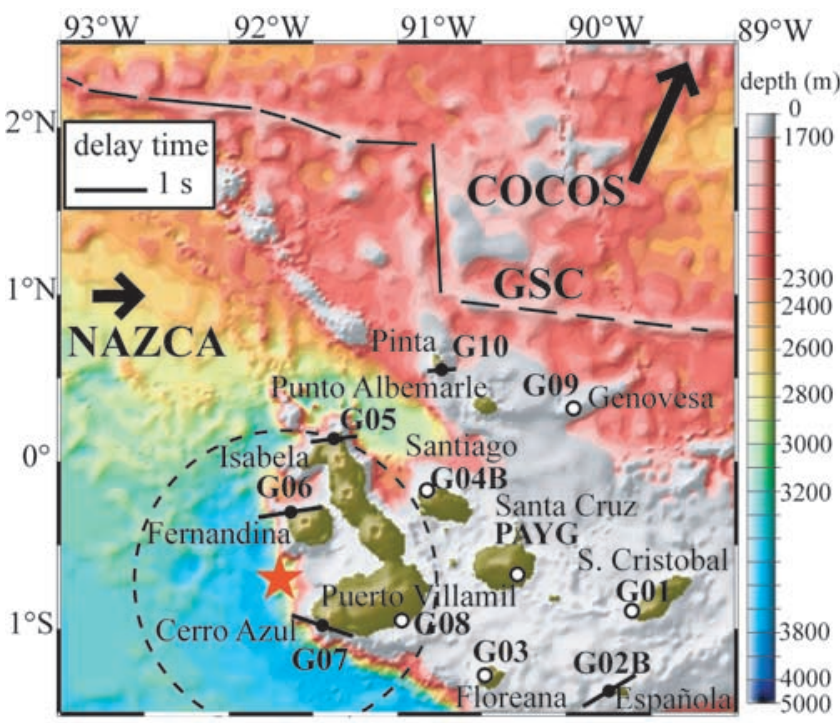

Figure 1. Shear-wave splitting beneath the Galápagos archipelago. Dots denote the positions of stations, and solid lines indicate the orientation $\phi$ of the fast shear-wave direction, with line length proportional to the delay time $\delta t$. Open circles are stations where no splitting was detected. Bathymetric data were compiled by W. Chadwick, Oregon State University; contour interval is $100 \mathrm{~m}$ for depths between 1700 and $4000 \mathrm{~m}$. Heavy arrows indicate the motions of the Nazca and Cocos plates (21.2 and $62.5 \mathrm{~mm} / \mathrm{yr}$, respectively) relative to a hotspot frame [Gripp and Gordon, 2002]. The dashed circle and star indicate an area of thinner than normal mantle transition zone and the approximate center of that area, respectively [Hooft et al., 2003].

[6] The Galápagos hotspot is located beneath the Nazca plate (Figure 1), which is moving eastward in a hotspot reference frame [Gripp and Gordon, 2002]. Morphological, geophysical, and geochemical observations indicate that the Galápagos hotspot interacts with the Galápagos Spreading Center (GSC) located $200 \mathrm{~km}$ to the north [Canales et al., 1997; Harpp and Geist, 2002]. The GSC strikes approximately east-west and accommodates intermediate-rate north-south spreading between the Cocos and Nazca plates. Here we report measurements of the splitting of teleseismic shear phases in the vicinity of the Galápagos hotspot, and we examine the relative contribution of asthenospheric flow, frozen lithospheric anisotropy, and partial melt to the observed pattern of splitting.

\section{Data Analysis}

[7] The seismic data are from a network of 10 portable broadband seismometers deployed on the Galápagos Islands (Figure 1) from 1999 to 2003, as well as the Global Seismographic Network broadband station PAYG on Santa Cruz. To ensure no interference from other seismic phases we selected SKS and SKKS phases from events at epicentral distances between $85^{\circ}$ and $145^{\circ}$. These phases are radially polarized at the core-mantle boundary, where they are generated by P-to-S conversion.
They are thus affected by anisotropy only along the upgoing portion of the wave path. Because these waves travel steeply through the mantle they have poor vertical resolution but good lateral resolution. We also selected $\mathrm{S}$ phases from events deeper than $400 \mathrm{~km}$ and at distances from $20^{\circ}$ to $85^{\circ}$. Choosing deep events limits the effect of source-side upper mantle anisotropy. We used events with $\mathrm{m}_{\mathrm{b}} \geq 5.5$ and a signal-to-noise ratio on the radial component and dominant S-wave component greater than 2:1 for core-phase and direct-S analysis, respectively.

[8] We assumed that anisotropy beneath the Galápagos is confined to a single uniform layer, and we used two methods to determine the shear-wave splitting parameters: the polarization $\phi$ of the fast shear wave and the delay time $\delta t$ between the fast and slow shear waves. At each station, we first analyzed individual events, and we then stacked the data from multiple events to improve the signal-to-noise ratio. For individual records, we used the method of Silver and Chan [1991] to compute the splitting parameters. We examined S phases with a horizontal particle motion linearization method. Core phase were analyzed with two methods: horizontal particle motion linearization and transverse energy minimization. The stacking method of Wolfe and Silver [1998] yielded more robust splitting parameters and reduced $95 \%$ confidence domains compared with the analyses of individual events. Following Wolfe and Silver [1998], the traces were band-pass filtered between 0.02 and $1 \mathrm{~Hz}$.

\section{Results}

[9] Analysis of individual splitting measurements yielded resolvable delay times at only three stations: Punto Albemarle on Isabela (G05), Cerro Azul on Isabela (G07), and Pinta (G10). (Auxiliary material ${ }^{1}$ gives the individual splitting measurements at each station). Splitting was not resolved at the other stations from single-event analysis. Examples of both resolved and null splitting measurements are shown in Figure 2. Null measurements are characterized by the absence of energy on the transverse component and therefore a linear particle motion in the horizontal plane.

[10] Stacking individual measurements provides the best constraints on splitting parameters. At five stations along the western and southern edge of the archipelago, delay times range from $0.4 \pm 0.1 \mathrm{~s}$ to $0.9 \pm 0.5 \mathrm{~s}$ (Table 1). The fast polarization directions are $59 \pm 7^{\circ}$ beneath Española (G02B), $83 \pm 9^{\circ}$ beneath Vulcan Wolfe (G05), $81 \pm 11^{\circ}$ beneath Fernandina (G06), $109 \pm 17^{\circ}$ at Cerro Azul (G07), and $86 \pm 10^{\circ}$ beneath Pinta (G10). Shear-wave splitting is not apparent $(\delta t<0.2 \mathrm{~s})$ at one station along the southern edge (Floreana, G03) and at stations in the center and on the eastern side of the archipelago: Santa Cruz (PAYG); San Cristobal (G01); Santiago (G04 and G04B); Puerto Villamil, Isabela (G08); and Genovesa (G09). Where splitting was detected from individual events the fast polarization directions are consistent with those seen with the stacking method. The delay times are smaller with the stacking method, however, because noise affects the small-amplitude

${ }^{1}$ Auxiliary material is available at $\mathrm{ftp}: / / \mathrm{ftp}$.agu.org/apend/gl/ 2005 GL024014. 
1)

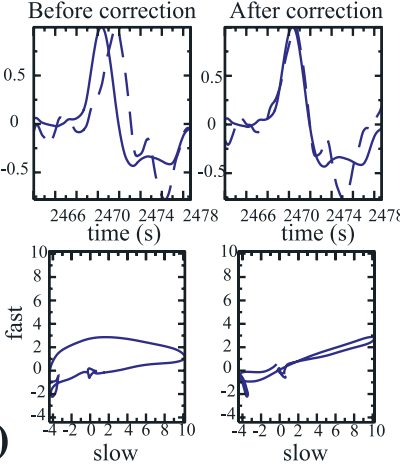

2)

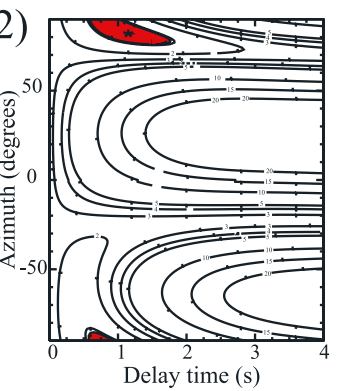

1)
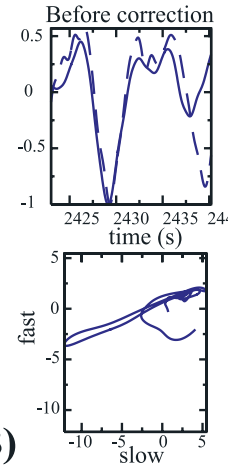
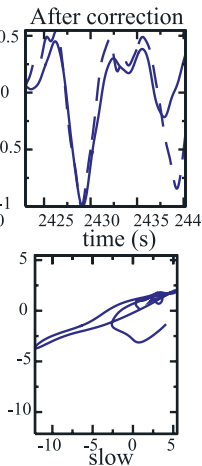

2)

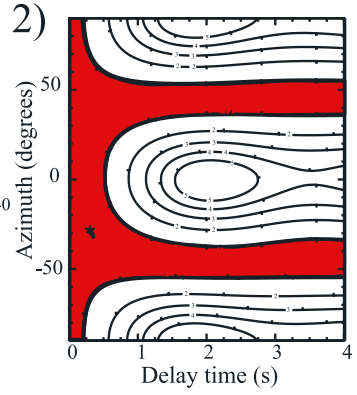

Figure 2. Examples of shear-wave splitting results from a single event at stations G05 and G08, respectively, showing (a) resolved splitting and (b) a null measurement. (1) Fast and slow shear waveforms and particle motions. (2) Contour plots of energy on the corrected transverse component for all possible values of $\phi$ and $\delta t$. The star denotes the minimum value. The shaded region is the $95 \%$ confidence interval, and the contours are multiples of this interval.

transverse component of core phases more strongly. Splitting at Española (G02B) and Fernandina (G06) was not seen in records from individual events; these stations have particularly high swell-induced seismic noise and benefit from the improvement in signal to noise of the stacking method.

\section{Discussion and Conclusion}

[11] Where splitting is detected, delay times decrease northward toward the GSC and the fast polarization directions are close to the direction of the Nazca plate in a hotspot reference frame [Gripp and Gordon, 2002], with the exception of Española (G02B), where $\phi$ is $59 \pm 7^{\circ}$. The decrease in delay times toward the spreading center might reflect ridge-related upwelling. The observed polarization directions clearly differ from the direction of fossil lithospheric anisotropy, which should be approximately northsouth, parallel to current plate spreading. In the Galápagos region lithospheric anisotropy may be small because the lithospheric mantle is thin, or anisotropy may have been erased or reset in the direction of absolute plate motion. We infer that the splitting observations are dominated by the asthenosphere and are the result of horizontal shear induced by differential motion between the subasthenospheric mantle and the overlying Nazca plate. Our polarization orientations are consistent with splitting observed at other islands in the Pacific [Russo and Okal, 1998; Wolfe and Silver, 1998], where little influence of fossil lithosphere is seen and fast directions are approximately in the direction of absolute plate motion.

[12] An important and robust finding of this experiment is the apparent isotropy, or small anisotropy, observed in the central Galápagos area. Moving from the leading edge of the Galápagos hotspot in the direction of absolute plate motion, there is a rapid change from splitting with a consistent orientation to no splitting (excepting G02B). We discuss four possible causes for the absence of shearwave splitting in the center of the Galápagos archipelago:

[13] (i) Upwelling is expected beneath a hotspot, and if there is no effect of melt or water on LPO vertical mantle flow would result in little shear-wave splitting [Mainprice and Silver, 1993]. Hooft et al. [2003] locate thinning of the mantle transition zone within an area approximately $100 \mathrm{~km}$ in radius centered $40 \mathrm{~km}$ to the southwest of Fernandina. Body-wave and surface-wave tomographic images indicate that the low-velocity volume bends northeastward toward the central Galápagos in the upper $150 \mathrm{~km}$ of the mantle [Toomey et al., 2002; Villagomez et al., 2004]. Thus strictly vertical flow through the entire thickness of the asthenosphere beneath the central Galápagos is unlikely.

[14] (ii) The presence of two anisotropic layers, with perpendicular fast axes and similar $\delta t$ values, also results in negligible shear-wave splitting. This model is consistent with the expected orientations of anisotropy in the lithosphere and asthenosphere from ridge spreading (northsouth) and plate-induced shear (east-west), respectively. However, the rapid spatial change from consistently oriented anisotropy to lack of anisotropy requires that any two such layers be confined to the area beneath the central Galápagos only, a geometry we consider unlikely. Because of the sparse measurements of resolved splitting we cannot investigate the presence of multiple anisotropic layers further.

[15] (iii) The flow field associated with plume-ridge interaction may be complex and result in small net delay times. For example, the fluid dynamic model of Kaminski and Ribe [2002] predicts a rapidly changing flow field 200 to $400 \mathrm{~km}$ east and west of the Galápagos hotspot. This model does not include the effect of absolute plate motion, however (i.e., plate-spreading and absolute plate motion directions are assumed to be parallel), and thus shearinduced flow in areas comparatively unaffected by plume-

Table 1. Shear-Wave Splitting Parameters and 1- $\sigma$ Errors at Each Station From the Stacking Method

\begin{tabular}{lccc}
\hline \multicolumn{1}{c}{ Station } & Number of Phases & $\Phi$, deg & $\delta t, \mathrm{~s}$ \\
\hline G01 & 5 & Null & Null \\
G02\&G02B & 6 & $59 \pm 7$ & $0.9 \pm 0.3$ \\
G03 & 9 & Null & Null \\
G04\&G04B & 6 & Null & Null \\
G05 & 6 & $83 \pm 9$ & $0.7 \pm 0.2$ \\
G06 & 5 & $81 \pm 11$ & $0.9 \pm 0.3$ \\
G07 & 3 & $109 \pm 17$ & $0.9 \pm 0.5$ \\
G08 & 7 & Null & Null \\
G09 & 10 & Null & Null \\
G10 & 5 & $86 \pm 10$ & $0.4 \pm 0.1$ \\
PAYG & 7 & Null & Null \\
\hline
\end{tabular}


plate interaction is parallel to plate spreading. Nevertheless, we note the spatial coincidence of the predicted complex and rapidly evolving flow with the region that lacks measurable anisotropy. In addition, this mechanism may provide an explanation for the anomalous polarization orientation at Española (G02B) (Figure 1).

[16] (iv) The effects of partial melt on upper mantle anisotropy are not straightforward. Laboratory experiments suggest that the presence of melt randomizes the orientations of the olivine $a$-axes, thereby reducing the net anisotropy of the medium [Holtzman et al., 2003]. Furthermore, the same experiments suggest that when melt segregates and forms networks of weak shear zones, the $a$-axes align perpendicular instead of parallel to the shear direction. In the Galápagos area there appears to be a correlation between the region of apparent isotropy and anomalously low upper mantle velocities between 50 and $80 \mathrm{~km}$ depth interpreted as due to partial melt [Villagomez et al., 2004]. Although the low-velocity volume is spatially more confined (between Santiago, Pinta, and Genovesa), the presence of melt beneath the center of the Galápagos archipelago may weaken mantle fabric and thus reduce splitting delay times. At continental convergent margins weak splitting also appears to be associated with partial melt. In these areas, splitting delay times are typically no larger than those for the crust alone, perhaps because passage of melt through the lithosphere has destroyed fabric [Silver, 1996].

[17] Where observed, shear-wave splitting in the Galápagos archipelago is the result of asthenospheric flow due to plate drag. Beneath the center of the archipelago apparent isotropy may be due to either the presence of melt in the upper mantle or the complex and rapidly changing flow field in the proximity of the ridge and the hotspot. In the Pacific basin, the absence of detectable splitting at several oceanic stations [Russo and Okal, 1998; Wolfe and Silver, 1998] may indicate that hotspots commonly affect upper mantle anisotropy in this manner.

[18] Acknowledgments. We thank G. Barruol, D. Villagomez, P. Ryan, B. Ildefonse, G. Bokelmann, and M. Savage for fruitful discussions and M. Fouch and B. Holtzman for constructive reviews. We acknowledge the Parque National Galápagos for permission to work in the area and M. Hall and the Estación Científica Charles Darwin (ECCD) for logistical support. We are grateful to developers of the SAC and GMT software. This work was supported by the French Program Dynamique et Evolution de la Terre Interne and by the National Science Foundation under grants OCE-9908695, OCE-0221549, and OCE-0221634.

\section{References}

Bjarnason, I. T., P. G. Silver, G. Rümpker, and S. C. Solomon (2002), Shear wave splitting across the Iceland hot spot: Results from the ICEMELT experiment, J. Geophys. Res., 107(12), 2382, doi:10.1029/ 2001JB000916.

Blackman, D. K., and J.-M. Kendall (1997), Sensitivity of teleseismic body waves to mineral texture and melt in the mantle beneath a mid-ocean ridge, Philos. Trans. R. Soc. London, Ser. A, 355, 217-231.

Canales, J. P., J. J. Dañobeitia, R. S. Detrick, E. E. E. Hooft, R. Bartolomé, and D. F. Naar (1997), Variations in axial morphology along the Galápagos Spreading Center and the influence of the Galápagos hotspot, J. Geophys. Res., 102, 27,341-27,354.
Geist, D. J., W. M. White, and A. R. McBirney (1988), Plume-asthenosphere mixing beneath the Galápagos Archipelago, Nature, 333, 657660 .

Graham, D. W., D. M. Christie, K. S. Harpp, and J. E. Lupton (1993), Mantle plume helium in submarine basalts from the Galápagos platform, Science, 262, 2023-2026.

Gripp, A. E., and R. G. Gordon (2002), Young tracks of hotspots and current plate velocities, Geophys. J. Int., 150, 321-361.

Harpp, K. S., and D. Geist (2002), Wolf-Darwin lineament and plume-ridge interaction in northern Galápagos, Geochem. Geophys. Geosyst., 3(11), 8504, doi:10.1029/2002GC000370

Holtzman, B. K., D. L. Kohlstedt, M. E. Zimmerman, F. Heidelbach, T. Hiraga, and J. Hustoft (2003), Melt segregation and strain partitioning: Implications for seismic anisotropy and mantle flow, Science, 301, $1227-1230$.

Hooft, E. E. E., D. R. Toomey, and S. C. Solomon (2003), Anomalously thin transition zone beneath the Galápagos hotspot, Earth Planet. Sci. Lett., 216, 55-64.

Kaminski, E., and N. M. Ribe (2002), Timescales for the evolution of seismic anisotropy in mantle flow, Geochem. Geophys. Geosyst., 3(8), 1051, doi:10.1029/2001GC000222.

Mainprice, D., and P. G. Silver (1993), Interpretation of SKS-waves using samples from the subcontinental lithosphere, Phys. Earth Planet. Inter, 78, 257-280.

McBirney, A. R., and H. Williams (1969), Geology and Petrology of the Galápagos Islands, Mem. Geol. Soc. Am., 118, 197 pp.

Montelli, R., G. Nolet, F. A. Dahlen, G. Masters, E. R. Engdahl, and S.-H. Hung (2004a), Finite-frequency tomography reveals a variety of plumes in the mantle, Science, 303, 338-343.

Montelli, R., G. Nolet, F. A. Dahlen, and G. Masters (2004), Plumes or not? Yes, and plenty!, Eos Trans. $A G U, 85(47)$, Fall Meet. Suppl., Abstract V35G-05.

Russo, R. M., and E. A. Okal (1998), Shear wave splitting and upper mantle deformation in French Polynesia: Evidence for small-scale heterogeneity related to the Society hotspot, J. Geophys. Res., 103, 15,089-15,107.

Silver, P. G. (1996), Seismic anisotropy beneath the continents: Probing the depths of geology, Annu. Rev. Earth Planet. Sci., 24, 385-432.

Silver, P. G., and W. W. Chan (1991), Shear wave splitting and subcontinental deformation, J. Geophys. Res., 96, 16,429-16,454.

Sleep, N. H. (1990), Hotspots and mantle plumes: Some phenomenology, J. Geophys. Res., 95, 6715-6736.

Toomey, D. R., E. E. Hooft, S. C. Solomon, D. E. James, and M. L. Hall (2002), Seismic evidence for a plume beneath the Galápagos hotspot, Eos Trans. AGU, 83(47), Fall Meet. Suppl., Abstract S72C02.

Villagomez, D. R., D. R. Toomey, E. E. Hooft, and S. C. Solomon (2004), Upper mantle structure beneath the Galápagos hotspot from surface wave tomography, Eos Trans. AGU, 85(47), Fall Meet. Suppl., Abstract V51B0571 .

Walker, K. T. (2003), Exploring problems in tectonics and geodynamics with seismology, Ph.D. thesis, 272 pp., Stanford Univ., Stanford, Calif.

Walker, K. T., G. H. R. Bokelmann, and S. L. Klemperer (2001), Shearwave splitting to test mantle deformation models around Hawaii, Geophys. Res. Lett., 28, 4319-4322.

Wolfe, C. J., and P. G. Silver (1998), Seismic anisotropy of oceanic upper mantle: Shear wave splitting methodologies and observations, J. Geophys. Res., 103, 749-771.

Zhang, S., and S. Karato (1995), Lattice preferred orientation of olivine aggregates deformed in simple shear, Nature, 375, 774-777.

P. G. Burkett, P. G. Silver, and S. C. Solomon, Department of Terrestrial Magnetism, Carnegie Institution of Washington, Washington, DC 20015, USA. (burkett@dtm.ciw.edu; silver@dtm.ciw.edu; scs@dtm.ciw.edu)

F. R. Fontaine, Laboratoire de Tectonophysique, ISTEEM, CNRS/ Université Montpellier II, F-34095 Montpellier cedex 5, France. (fontaine@) dstu.univ-montp2.fr)

E. E. E. Hooft and D. R. Toomey, Department of Geological Sciences, University of Oregon, 1272 Cascade Hall, Eugene, OR 97403, USA. (emilie@uoregon.edu; drt@uoregon.edu) 